\title{
ESTRATÉGIAS PARA A TOMADA DE DECISÃO NO LANÇAMENTO DE UM NOVO PRODUTO: O CASO DE UMA EMPRESA DO SETOR ALIMENTÍCIO
}

\author{
Daniel de Souza Valotto \\ Graduação em Administração. Especialista em Formação Docente para EAD. Mestrando em \\ Inovação e Tecnologia. \\ E-mail: danielvaloto@gmail.com \\ Renê Bergel \\ Graduação em Quimico Industrial. Especialista em Administração da Produção e Logística \\ Empresarial. Mestrado em Administração. Atualmente é Professor da Pontifícia Universidade Católica \\ do Paraná. \\ E-mail: rene.bergel@pucpr.br
}

\begin{abstract}
Resumo
Esta pesquisa tem por objetivo identificar as preferências do consumidor vegetariano e vegano no município de Curitiba, averiguar o potencial mercado e demanda vegana/vegetariana no município e apontar estratégias de fidelização e ações de marketing necessárias para atingir este público. A pesquisa adota uma abordagem qualitativa, por meio de entrevistas semiestruturadas com clientes típicos da empresa, que posteriormente originou uma Survey distribuída por e-mail e redes sociais à potenciais consumidores. A investigação possibilitou reunir diferentes métodos e técnicas de avaliação de mercado para dar suporte a tomada de decisões estratégicas. Tais decisões corroboram a literatura a respeito da necessidade de conhecimento sobre 0 as incertezas do ambiente para decisões mais assertivas. As ações realizadas e sugeridas nesta pesquisa podem ser adotadas por outras empresas que pretendam ofertar novos produtos ao mercado, pois propiciam uma ampla visão de aspectos como apuração do mercado potencial, averiguação das preferências e percepções do consumidor sobre o projeto e possíveis formas de potencializar a efetivação da compra.
\end{abstract}

Palavras-chave: Tomada de decisão. Inovação de produto. Preferências do consumidor. Demanda. Ações de marketing.

\begin{abstract}
This research aims to identify the preferences of the vegetarian and vegan consumers in the city of Curitiba, ascertain the potential market and vegan/vegetarian demand in the city, and point out loyalty strategies and marketing actions necessary to reach this audience. The research adopts a qualitative approach, through semi-structured interviews with typical customers of the company, which subsequently originated a Survey distributed by e-mail and social networks to potential consumers. The investigation made it possible to bring together different methods and techniques of market assessment to support strategic decision-making. Such decisions corroborate the literature regarding the need for knowledge about the uncertainties of the environment for more assertive decisions. The actions carried out and suggested in this research can be adopted by other companies that intend to offer new products to the market, as they provide a wide view of aspects such as the determination of the potential market, the verification of consumer preferences and perceptions about the project and possible ways to enhance the purchase.
\end{abstract}

Keywords: Decision-making. Product innovation. Consumer preferences. Demand. Marketing actions. 


\section{INTRODUÇÃO}

São considerados vegetarianas as pessoas que excluem carne de sua alimentação, já os veganos são os que deixam de consumir alimentos provenientes de exploração animal - não apenas carne - além de rejeitarem o uso de produtos testados em animais (MOREIRA; ACEVEDO, 2015; MALEK; UMBERGER, 2021). O setor de alimentação vegetariana e vegana apresenta indicativos de crescimento no mercado mundial: de acordo com a revista Forbes (2018), aproximadamente $70 \%$ da população mundial estava reduzindo ou excluindo carnes de sua alimentação cotidiana.

No Brasil, esta tendência também é crescente e o país já figura entre os 10 países com mais adeptos de vegetarianos no mundo (WORLDATLAS, 2019). A partir de uma pesquisa encomendada ao IBOPE, a Sociedade Vegana Brasileira (SVB) indica que $14 \%$ da população brasileira se declarava vegetariana, e destas, $33 \%$ se denominava vegana (SVB, 2019). Com um progressivo interesse por uma alimentação mais saudável, o mercado vegano aponta um crescimento de $40 \%$ ao ano no Brasil (CARREIRO, 2017).

Em contraponto, outra demanda crescente dos consumidores é a economia de tempo. Uma pesquisa realizada pela International Stress Management Association Brazil, revela que $62 \%$ dos brasileiros indicavam falta de tempo para conciliar trabalho, estudos, família, casa, entre outras tarefas do cotidiano, fato que afetava a qualidade da alimentação. O mesmo estudo indica que $32 \%$ dos entrevistados se queixaram de distúrbios alimentares devido à falta de tempo para cuidar da alimentação (GLOBO CIÊNCIA, 2012).

Observando tais tendências, os gestores de uma empresa de alimentação vegetariana de pequeno porte localizada em Curitiba, capital do estado do Paraná denominada como "Beta" - vislumbram a possibilidade de expandir seus potenciais clientes para atingir também os adeptos do veganismo e inovar seu mix de produtos, ofertando alimentos veganos na forma congelada. Desta maneira, esta pesquisa teve por objetivo identificar as preferências do consumidor vegetariano e vegano no município de Curitiba, averiguar o potencial mercado e demanda vegana/vegetariana no município e apontar estratégias de fidelização e ações de marketing necessárias para atingir este público.

O artigo está divido da seguinte forma: o tópico subsequente apresenta o referencial teórico sobre tomada de decisão e inovação em produtos, o tópico 3 indica os procedimentos metodológicos adotados na investigação. A seção 4 caracteriza a empresa, indica e explora as intervenções sugeridas, bem como apresenta os resultados apurados. O último tópico apresenta a discussão, aponta limitações e sugere estudos futuros.

\section{REFERENCIAL TEÓRICO}

A tomada de decisão estratégica é um processo complexo em que gestores coletam e analisam variadas informações para subsidiar a escolha de uma ação específica (CALABRETTA; GEMSER; WIJNBERG, 2017; SAMBA et al, 2020). Tais direcionamentos não podem ser sustentados apenas em emoções e percepções tácitas do gestor, é imperativo se ater a informações de fontes confiáveis e especializadas (TREFFERS; KLARNER; HUY, 2020). 
As decisões de cunho estratégico costumam se referir a ações com impacto em larga escala, de difícil reversão e implicam no futuro da organização (PAPULOVA; GAZOVA, 2016). Tais ações podem se traduzir em um reposicionamento estratégico, lançamento de novos produtos, aumento de públicoalvo, entre outros (WANG et al., 2021).

Quando se trata especificamente de decisões estratégicas referentes a inovação em produtos, Terra, Barbosa e Bouzada (2015) sustentam que tais decisões possibilitam à organização aumento de vendas, público e lucro, objetivos os quais a maioria das empresas percorre.

O Manual de Oslo (OECD/EUROSTAT, 2018) compreende inovação em produtos como a introdução de um bem ou serviço novo ou com significativa melhoria de características ou de uso. A inovação em produtos pode ser de forma radical, quando apresenta alto grau de inovação, ou de forma incremental, dada quando há pequenas inovações em relação ao produto anterior (LENNERTS; SCHULZE; TOMCZAK, 2019).

Tidd e Bessant (2015) destacam vantagens que as empresas podem adquirir ao se inovarem seus produtos, como oferecer aos consumidores algo que outas empresas não conseguem ou desenvolver produtos e serviços de maneira que os concorrentes tenham dificuldade em dominar e copiar, ou cobre pela utilização de sua inovação, criando vantagem competitiva.

A inovação de produtos para adquirir vantagens frente aos concorrentes motivou os sócios da empresa Beta a vislumbrarem uma inovação incremental em seu mix de produtos. A empresa pretendia oferecer uma nova modalidade de preparo de alimentos e oferecer tal solução à um novo público. Para validar a viabilidade do projeto, desenvolveu-se uma pesquisa de mercado a fim de sustentar a tomada de decisão dos gestores.

\section{METODOLOGIA}

Para alcançar os objetivos propostos, foram adotadas as técnicas de: 1Survey (BARBETTA, 2002) para observar as preferências dos clientes; 2- Funil de Vendas (MARQUES; LEVI, 2020) para estimar o mercado potencial dos novos clientes; e 3- ações de marketing (GONÇALVES; MACHADO; MARQUES, 2020) para fidelização de clientes.

Inicialmente, deu-se a identificação das preferencias do consumidor vegetariano e vegano por meio de entrevistas semiestruturadas com clientes selecionados aleatoriamente da base de dados da empresa. As entrevistas ocorreram no segundo semestre de 2019. Os dados das entrevistas foram categorizados pela técnica de codificação de primeiro ciclo (SALDAÑA, 2013) no software Atlas.TI a fim elucidar padrões.

Em seguida, foi elaborado um questionário estruturado fechado (BARBETTA, 2002) aplicado à base de dados da empresa e grupos do Facebook sobre alimentação vegetariana e vegana em Curitiba. Técnicas semelhantes foram utilizas por Anjos et al. (2014) na identificação de fatores que influenciavam consumidores na escolha de restaurantes.

$\mathrm{Na}$ sequência, a partir dos resultados do questionário e de informações sobre o município de Curitiba, renda dos potenciais consumidores e outras informações inerentes ao conceito do produto, foi desenvolvido um funil de vendas, ferramenta utilizada para dirimir barreiras que possam reduzir a probabilidade de 
compra de um consumidor (MARQUES; LEVI, 2020). Este método também permite à empresa não apenas identificar o público potencial, mas também realizar prospecções de receitas com sua comercialização.

Por fim, as estratégias de fidelização e ações de marketing foram sugeridas conforme orçamento planejado pela Beta e capacidade de recursos físicos, tecnológicos e humanos que a empresa disponibiliza (MEIRELLES, 2020).

O detalhamento de cada ação é explicado na seção a seguir.

\section{APRESENTAÇÃO E ANÁLISE dOS RESULTADOS}

A empresa objeto deste estudo pertence ao mercado de alimentação vegetariana, sendo uma empresa de pequeno porte localizada em Curitiba, no estado do Paraná. Para manter o anonimato, esta pesquisa tratará a empresa pelo nome fictício Beta. A empresa Beta atua no mercado curitibano há 3 anos, oferecendo pratos vegetarianos frescos e congelados com entrega em domicílio. A Beta se define como uma empresa que ajuda pessoas que possuem um estilo de vida saudável a resolver suas necessidades alimentares com pratos vegetarianos.

Observando tendências do mercado, os dois sócios da Beta possuem a intenção de aumentar sua segmentação de clientes, visando atingir pessoas veganas que não disponham de muito tempo para preparar suas próprias refeições, oferecendo pratos veganos na forma congelada. A fim de terem mais informações concretas para a tomada de decisão sobre o potencial do investimento, os sócios solicitaram um estudo de viabilidade para identificar as preferências do consumidor vegetariano e vegano no município de Curitiba, averiguar o potencial mercado e demanda vegana/vegetariana no município e apontar estratégias de fidelização e ações de marketing necessárias para atingir este público.

As respostas a estes questionamentos são apresentadas nesta seção. Com base nos conhecimentos adquiridos pelo autor durante sua formação acadêmica e atuação no mercado e técnicas de mercado específicas, foram adotados os seguintes mecanismos: para identificar o potencial mercado foi adotado a técnica de funil de demanda à população de Curitiba; para verificar a aceitação do potencial consumidor a modalidade da refeição, foi realizado entrevistas semiestruturadas e questionário fechado; a indicação de ações de marketing foi sugerida conforme conhecimentos e experiências prévios do autor.

\subsection{ESTUDO DAS PREFERÊNCIAS DOS CLIENTES}

Inicialmente foi desenvolvida uma pesquisa qualitativa através de questionário semiestruturado aberto com 3 clientes autodeclarados veganos, oriundos da base de dados da Beta e selecionados aleatoriamente. O intuito destas entrevistas foi confirmar as hipóteses lançadas pela empresa e compreender as motivações que estes clientes consideram no momento da aquisição de alimentos veganos. As entrevistas duraram aproximadamente 25 minutos. Após a transcrição das entrevistas, foi realizada codificação de primeiro ciclo, nas formas descritiva e inicial, atribuindo-se rótulos básicos aos dados a fim de examinar e comparar as similaridades e diferenças (SALDAÑA, 2013).

A partir das análises, foi possível traçar padrões entre as respostas e agrupar palavras-chave em categorias preestabelecidas que posteriormente serviram de base para estruturar um questionário quantitativo fechado. Para tanto, 
as variáveis de interesse foram levantadas, estabelecidas as unidades de medidas e formas de mensuração, elaboração das perguntas, verificação da clareza das perguntas e obviedade das respostas (BARBETTA, 2002).

Desta forma, foram desenvolvidas 23 perguntas objetivas que foram testadas e validadas com 5 consumidores veganos. Na sequência, o questionário foi aplicado através da plataforma online Qualtrics e distribuído por e-mail à base de dados de clientes da Beta e em grupos no Facebook sobre alimentação vegana em Curitiba. Ao logo de 28 dias, 454 pessoas começaram a responder o questionário. Entretanto, foram consideradas como respostas válidas para a investigação apenas os respondentes que afirmaram ser adeptos da alimentação vegana e que responderam a todas as questões, resultando em 353 respostas.

Após o encerramento do questionário, os dados foram tabulados em planilha eletrônica. Em síntese, pode-se evidenciar que $75 \%$ dos entrevistados consomem alimentos veganos todos os dias, $86 \%$ prefere escolher os alimentos de seu prato ao invés de menus prontos, $60 \%$ preferem refeições prontas à restaurantes e a falta de tempo foi o maior motivo apontado para que comam fora de casa. Entre os pratos mais consumidos estão arroz, feijão e legumes. Estes dados confirmam as hipóteses da organização e nortearão para a diferenciação e percepção de valores pelos clientes. 
Tabela 1 - Sumarização das respostas do questionário

\begin{tabular}{|c|c|c|c|c|c|c|c|}
\hline \multirow{3}{*}{$\begin{array}{l}\text { PERGUNTA } \\
\text { Q1 - Você é adepto/simpatizante de alimentação } \\
\text { vegetariana/vegana? }\end{array}$} & \multicolumn{7}{|c|}{ RESPOSTAS } \\
\hline & \multirow{2}{*}{\multicolumn{4}{|c|}{$\begin{array}{c}\text { Sim } \\
96.19 \%\end{array}$}} & \multicolumn{3}{|c|}{ Não } \\
\hline & & & & & \multicolumn{3}{|c|}{$3.81 \%$} \\
\hline \multirow{2}{*}{$\begin{array}{l}\text { Q2 - Com que frequência você consome alimentos } \\
\text { veganos? }\end{array}$} & Todo dia & $1-2$ dias/sem & 3-4 dias/sem & 5-6 dias/sem & cada 15 dias & $1 \mathrm{vez} / \mathrm{mês}$ & $<1 \mathrm{vez} / \mathrm{mês}$ \\
\hline & $75.64 \%$ & $5.67 \%$ & $7.08 \%$ & $5.67 \%$ & $1.98 \%$ & $0.85 \%$ & $3.12 \%$ \\
\hline Q3 - Quais tipos de alimentos veganos você mais & Massas & \multicolumn{2}{|c|}{ Carnes veganas } & Hortaliças & Saladas & Grãos & Outros \\
\hline consome? & $14.76 \%$ & \multicolumn{2}{|c|}{$10.20 \%$} & $23.70 \%$ & $23.31 \%$ & $24.10 \%$ & $3.92 \%$ \\
\hline \multirow{4}{*}{$\begin{array}{l}\text { Q4 - Em quais lugares você costuma adquirir/consumir } \\
\text { alimentos veganos? } \\
\text { Q5 - Qual das afirmações abaixo mais se adequa a sua } \\
\text { preferência? }\end{array}$} & Feiras & Mercado & Internet & Loja especial. & Restaurantes & Fabricante & Outros \\
\hline & $24.42 \%$ & $28.28 \%$ & $3.86 \%$ & $18.73 \%$ & $13.90 \%$ & $4.63 \%$ & $6.18 \%$ \\
\hline & \multicolumn{4}{|c|}{ À lá carte } & \multicolumn{3}{|c|}{ Escolher alimentos } \\
\hline & \multicolumn{4}{|c|}{$13.60 \%$} & \multicolumn{3}{|c|}{$86.40 \%$} \\
\hline \multirow{2}{*}{$\begin{array}{l}\text { Q6 - Com que frequência você cozinha suas próprias } \\
\text { refeições em uma semana? }\end{array}$} & Todo dia & 1-2 dias/sem & 3-4 dias/sem & 5-6 dias/sem & cada 15 dias & $1 \mathrm{vez} / \mathrm{mês}$ & < 1 vez/mês \\
\hline & $35.13 \%$ & $17.00 \%$ & $24.65 \%$ & $15.86 \%$ & $2.27 \%$ & $0.85 \%$ & $4.25 \%$ \\
\hline \multirow[t]{2}{*}{ Q7 - Que tipo de pratos você mais consome? } & Sopas & Massas & Carnes & grãos & $\begin{array}{l}\text { Legumes, } \\
\text { vegetais }\end{array}$ & \multicolumn{2}{|c|}{ Básico (arroz, feijão) } \\
\hline & 3.54 & 14.73 & 10.5 & 14.33 & 30.77 & \multicolumn{2}{|c|}{29.67} \\
\hline \multirow{4}{*}{$\begin{array}{l}\text { Q8 - Quais dos fatores abaixo explicariam o fato de } \\
\text { você comer fora de casa? } \\
\text { Q9 - Quanto em média você gasta com o consumo de } \\
\text { um prato vegano fora de casa? }\end{array}$} & Falta tempo & Suja louça & Trabalho fora & Não cozinha & Conveniente & \multicolumn{2}{|c|}{ Outros } \\
\hline & $22.13 \%$ & $3.34 \%$ & $25.26 \%$ & $4.59 \%$ & $28.18 \%$ & \multicolumn{2}{|c|}{$16.49 \%$} \\
\hline & & & & Desvio Padrão & & & \\
\hline & $\mathrm{R} \$$ & 28.32 & $\mathrm{R} \$$ & & 19.38 & $\mathrm{R} \$$ & 375.51 \\
\hline Q10 - Quando você não tem tempo para cozinhar suas & Refeição & pronta, sendo nec & essária apenas es & uentá-la & & a um restauran & \\
\hline para você? & & & & & & $40.51 \%$ & \\
\hline Q11 - Você estaria disposto a comprar uma refeição veg & ana congelada $\mathrm{c}$ & ipleta, de proced & ncia confiável, c & o mesmo sab & um prato & Sim & Não \\
\hline $\begin{array}{l}\text { fresco, no qual você poderia montar sua própria refeição } \\
\text { retornáveis que barateariam o valor do produto e ainda }\end{array}$ & $\begin{array}{l}\text { tendo a convenie } \\
\text { ontribuisse para a }\end{array}$ & $\begin{array}{l}\text { icia de consumi-l } \\
\text { ustentabilidade? }\end{array}$ & ( & 型 & & $88.39 \%$ & $11.61 \%$ \\
\hline Q12 - Quanto você estaria disposto a pagar nesta & & & & Desvio Padrão & & & \\
\hline refeição completa vegana congelada? & $\mathrm{R} \$$ & 19.73 & $\mathrm{R} \$$ & & 9.29 & $\mathrm{R} \$$ & 86.29 \\
\hline Q13 - Em quais refeições você comeria estas & Café & lanhã & & Almoço & & & \\
\hline refeições? & & & & $63.03 \%$ & & & \\
\hline Q14 - Como você costuma aquecer alimentos & & & & Microondas & & & \\
\hline congelados? & 36. & & & $55.66 \%$ & & & \\
\hline O15 - Selecione até 5 dos atributos abaixo que você & Qualidade & Preço & Procedência & Reocomend. & Embalagem & Aparência & Disponibilid. \\
\hline considera mais importantes no momento de adquirir & $18.98 \%$ & $17.84 \%$ & $6.11 \%$ & $4.53 \%$ & $0.79 \%$ & $4.66 \%$ & $7.50 \%$ \\
\hline alimentos veganos. & Distância & Sustentabilid. & Proximidade & Variedade & Origem & & \\
\hline & $1.69 \%$ & $8.83 \%$ & $6.53 \%$ & $6.89 \%$ & $9.01 \%$ & & \\
\hline Q16 - Em relação ao preparo de um prato congelado & Autonomia & Conve & iência & Economia & de tempo & Prat & ade \\
\hline importante (selecione até 2 atributos). & $10.28 \%$ & 19. & & 28. & & & \\
\hline Q17 - Qual tamanho de embalagem você considera & & & & Desvio Padrão & & & \\
\hline (em gramas)? & & & & 122.62 & & & \\
\hline Q18 - Ainda falando sobre embalagem, quais dos itens & Biodegradável & Reciclável & Retornável & Boa vedação & Ver o produto & & \\
\hline $\begin{array}{l}\text { congelado vegano? } \\
\text { colato }\end{array}$ & $24.08 \%$ & $19.90 \%$ & $15.72 \%$ & $16.83 \%$ & $21.74 \%$ & & \\
\hline $\begin{array}{l}\text { Q19 - Em sua opinião, qual a validade ideal para } \\
\text { alimentos veganos congelados ainda serem }\end{array}$ & & & & Desvio Padrão & & & \\
\hline $\begin{array}{l}\text { considerados frescos para consumo sem perda de } \\
\text { sabor? }\end{array}$ & & & & 9.51 & & & \\
\hline Q20 - Qual a principal forma de você conhecer novos & Feiras & Internet & Redes sociais & Indicações & Mercados & Restaurantes & Outros \\
\hline produtos veganos? & $9.95 \%$ & $25.92 \%$ & $23.56 \%$ & $19.20 \%$ & $10.99 \%$ & $7.24 \%$ & $2.83 \%$ \\
\hline Q21 - Qual o seu sexo? & & Mas & ulino & & & Feminino & \\
\hline & & 19.2 & & & & $80.74 \%$ & \\
\hline Q22 - Ounl a sua faixa etária? & Até 19 anos & 20 a 29 anos & 30 a 39 anos & 40 a 49 anos & 50 a 59 anos & $60 \mathrm{o}$ & hais \\
\hline 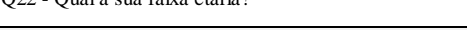 & $9.92 \%$ & $41.93 \%$ & $28.61 \%$ & $11.61 \%$ & $4.82 \%$ & & \\
\hline O23 - Oual a sua faixa de renda familiar? & Até 1.000 & $>1001 \leq 2 \mathrm{mil}$ & $>2001 \leq 3 \mathrm{mil}$ & $>3001 \leq 4 \mathrm{mil}$ & $>4000 \leq 5 \mathrm{mil}$ & $>5001 \leq 6 \mathrm{mil}$ & $>6.000$ \\
\hline Q25 - Quar a sua raixa de rencal Taminar! & $9.92 \%$ & $16.71 \%$ & $16.15 \%$ & $12.46 \%$ & $10.48 \%$ & $9.35 \%$ & $24.93 \%$ \\
\hline
\end{tabular}

\subsection{POTENCIAL MERCADO E DEMANDA VEGANA/VEGETARIANA EM CURITIBA}

Com base nas informações da pesquisa quantitativa disponíveis, foi desenvolvido um funil de vendas com o cálculo do potencial total de clientes veganos aderentes à proposta dos novos produtos da Beta. Esta técnica também foi empregada por Oliveira, Gois e Goldstein (2018) para determinar o potencial mercado em serviços orientados para o Telecom.

Nesse estudo, foram analisadas nove variáveis que delimitam o perfil de consumidor almejado baseadas na experiência do autor, que serão explanadas a seguir. 
(1) é relativo à localização da empresa, que irá abranger toda a cidade de Curitiba. Assim, o universo foi restringido à população do município, que de acordo com o Censo do IBGE em 2017, era de 1.908.359 habitantes;

(2) Não há dados recentes sobre a população vegetariana no país, mas uma pesquisa do IBOPE em 2012 apurou que 14\% dos brasileiros se declaravam vegetarianos. Também não há dados oficiais atuais acerca da população vegana no país, mas a Sociedade Vegetariana Brasileira infere a partir de outros países, que $33 \%$ dos vegetarianos são veganos. Como as refeições propostas pela Beta atendem tanto o público vegano como o vegetariano, serão utilizados os dados referentes ao público de vegetarianos, inferindo os mesmos $14 \%$ para a população de Curitiba, chegando a 267.170 habitantes;

(3) para calcular a influência da classe social na compra das refeições da Beta, foi utilizada a seguinte técnica: primeiramente foram definidos como potenciais compradores dos produtos da empresa os indivíduos pertencentes as classes sociais A, B1, B2 e C1, baseando-se em suas rendas mensais definidas pelo PNADIBGE (2014) e a própria base de dados da empresa. Em seguida, verificou-se a porcentagem que cada uma dessas classes representa na população de Curitiba a partir de dados do Critério Brasil distribuídos pela ABEP (2016)e finalmente, foi estimada uma probabilidade de cada uma das classes adquirir as refeições, chegando ao valor total de $30,36 \%$ da população vegana do município, o que representa 81.754 habitantes. A tabela 2 representa as informações.

Tabela 2 - Frequência de classe social em Curitiba

\begin{tabular}{cccc}
\hline Classe & Participação em Curitiba & Probabilidade de compra & Frequência \\
\hline A & $5,40 \%$ & $100 \%$ & $5,40 \%$ \\
\hline B1 & $8,20 \%$ & $75 \%$ & $6,15 \%$ \\
\hline B2 & $24,30 \%$ & $50 \%$ & $12,15 \%$ \\
\hline C1 & $27,60 \%$ & $25 \%$ & $6,90 \%$ \\
\hline TOTAL & $65,50 \%$ & - & $\mathbf{3 0 , 6 0 \%}$ \\
\hline
\end{tabular}

(4) $\mathrm{Na}$ pesquisa quantitativa foi identificado que $75 \%$ dos entrevistados consomem refeições veganas diariamente enquanto os demais $25 \%$ variam entre 6 vezes por semana e menos de uma vez ao mês. Assim, foi calculada a proporção de refeições consumidas por semana e em seguida calculada a média ponderada para se obter a frequência correta de consumo dos alimentos, resultando em $85,48 \%$, o que equivale a 69.885 habitantes, conforme indica a tabela 3.

Tabela 3 - Média ponderada dos dias de consumo de alimentos veganos

\begin{tabular}{cccc}
\hline \multicolumn{2}{c}{$\begin{array}{c}\text { Dias que consome } \\
\text { Alimentos veganos }\end{array}$} & $\begin{array}{c}\text { Proporção em } \\
\mathbf{7} \text { dias da semana }\end{array}$ & Média ponderada \\
\hline Todos os dias & $75.64 \%$ & 1.000 & $75.64 \%$ \\
\hline 2 dias por semana & $5.67 \%$ & 0.286 & $1.62 \%$ \\
\hline 4 dias por semana & $7.08 \%$ & 0.500 & $3.54 \%$ \\
\hline 6 dias por semana & $5.67 \%$ & 0.786 & $4.46 \%$ \\
\hline A cada 15 dias & $1.98 \%$ & 0.071428571 & $0.14 \%$ \\
\hline 1 vez por mês & $0.85 \%$ & 0.035714286 & $0.03 \%$ \\
\hline Menos de 1 vez por mês & $3.12 \%$ & 0.017857143 & $0.06 \%$ \\
\hline & TOTAL & & $\mathbf{8 5 . 4 8 2 5 0 \%}$ \\
\hline
\end{tabular}

(5) Também foi questionado na pesquisa o número de vezes que os consumidores compram a refeição pronta ou vão a um restaurante ao invés de cozinharem suas próprias refeições. Após realizar uma média ponderada, chegou-se 
ao resultado de que $36,18 \%$ dos respondentes ou 14.499 habitantes apontam este comportamento.

(6) ainda em consulta ao questionário, 59,49\% dos respondentes afirmaram que ao não prepararem seus alimentos, preferem comprar refeições pré-prontas em oposição a irem em restaurantes. Este número resultou em 8.596 habitantes, detalhados na tabela 4;

Tabela 4 - Proporção das vezes que o consumidor cozinha a própria refeição

\begin{tabular}{ccc}
\hline \multicolumn{2}{c}{ Dias que cozinha } & Proporção de vezes que não cozinha sua refeição \\
\hline Todos os dias & $35.13 \%$ & $0.00 \%$ \\
\hline 1 a 2 dias por semana & $17 \%$ & $13.36 \%$ \\
\hline 3 a 4 dias por semana & $24.65 \%$ & $12.33 \%$ \\
\hline 5 a 6 dias por semana & $15.86 \%$ & $3.40 \%$ \\
\hline A cada 15 dias & $2.27 \%$ & $2.11 \%$ \\
\hline 1 vez por mês & $0.85 \%$ & $0.82 \%$ \\
\hline Menos de 1 vez por mês & $4.25 \%$ & $4.17 \%$ \\
\hline TOTAL & & $\mathbf{3 6 . 1 8 2 3} \%$ \\
\hline
\end{tabular}

(7) este item se refere ao modo de preparo das refeições congeladas. Ao questionar os entrevistados sobre como costumam aquecer alimentos congelados, parte dos respondentes indicou que não consome alimentos que precisem ser aquecidos em forno microondas ou forno elétrico por acreditarem que este processo deteriora as propriedades dos alimentos. Decidiu-se excluir esta parcela de consumidores da demanda potencial (correspondentes a 7,78\%). Assim, resultam $92,22 \%$ dos clientes que não denotam problemas com a forma de aquecimento de refeições congeladas, ou 13.872 habitantes;

(8) ao perguntar em que canais costumam adquirir suas refeições, 27,22\% compram pelos canais em que a Beta atua (internet e loja física), valor que corresponde a 4.095 habitantes.

(9) a partir deste número de habitantes, foi estimada a quantidade de refeições que este público consumiria em um mês. Foi perguntado quais refeições (almoço e/ou janta) os clientes consumiriam os pratos congelados da Beta e a partir das respostas foi estimado o número de pratos por mês que uma pessoa consumiria, conforme tabela 5 .

Tabela 5 - Quantidade de refeições por pessoa ao ano

\begin{tabular}{cccc}
\hline Refeição & porcentagem & Dias/mês & № refeições \\
\hline Almoço & $63,03 \%$ & 30 & $\mathbf{1 9}$ \\
\hline Jantar & $30,32 \%$ & 30 & $\mathbf{9}$ \\
\hline TOTAL & & & $\mathbf{2 8}$ \\
\hline
\end{tabular}

Finalmente, para se chegar ao número total da demanda anual, bastou multiplicar a quantidade de consumidores potenciais delimitado no funil (4.095) pela quantidade de refeições consumida por uma pessoa em um mês (28), chegando a quantidade de 114.660 refeições por ano.

(10) definiu-se o Market share da Beta em 2.5\% desta demanda total potencial do município, resultando em 2.866 refeições mensais, quantia que representa aproximadamente 102 clientes. Este percentual justifica-se pelas delimitações aplicadas ao funil, onde apenas $0,12 \%$ da população total de Curitiba se enquadra nos requisitos e pelo estudo da concorrência na localidade. O resultado abrange apenas a população vegana e vegetariana, sem incluir potenciais clientes 


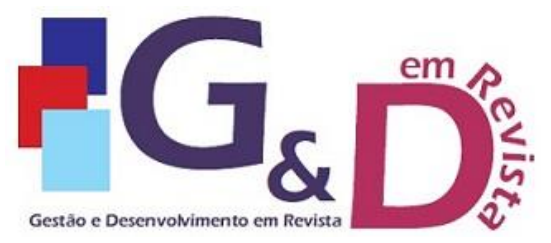

Gestão e Desenvolvimento em Revista V. 6, N. 2, jul-dez/2020, p. 68-81.

ISSN online: $2446-8738$

Artigo recebido em: $27 / 08 / 2020$

Artigo aprovado em: 13/01/2021

que se interessem por alimentação saudável, mas não são veganos/vegetarianos. A representação do funil de demanda é representada na figura 1.

Figura 1 - Representação do funil de demanda

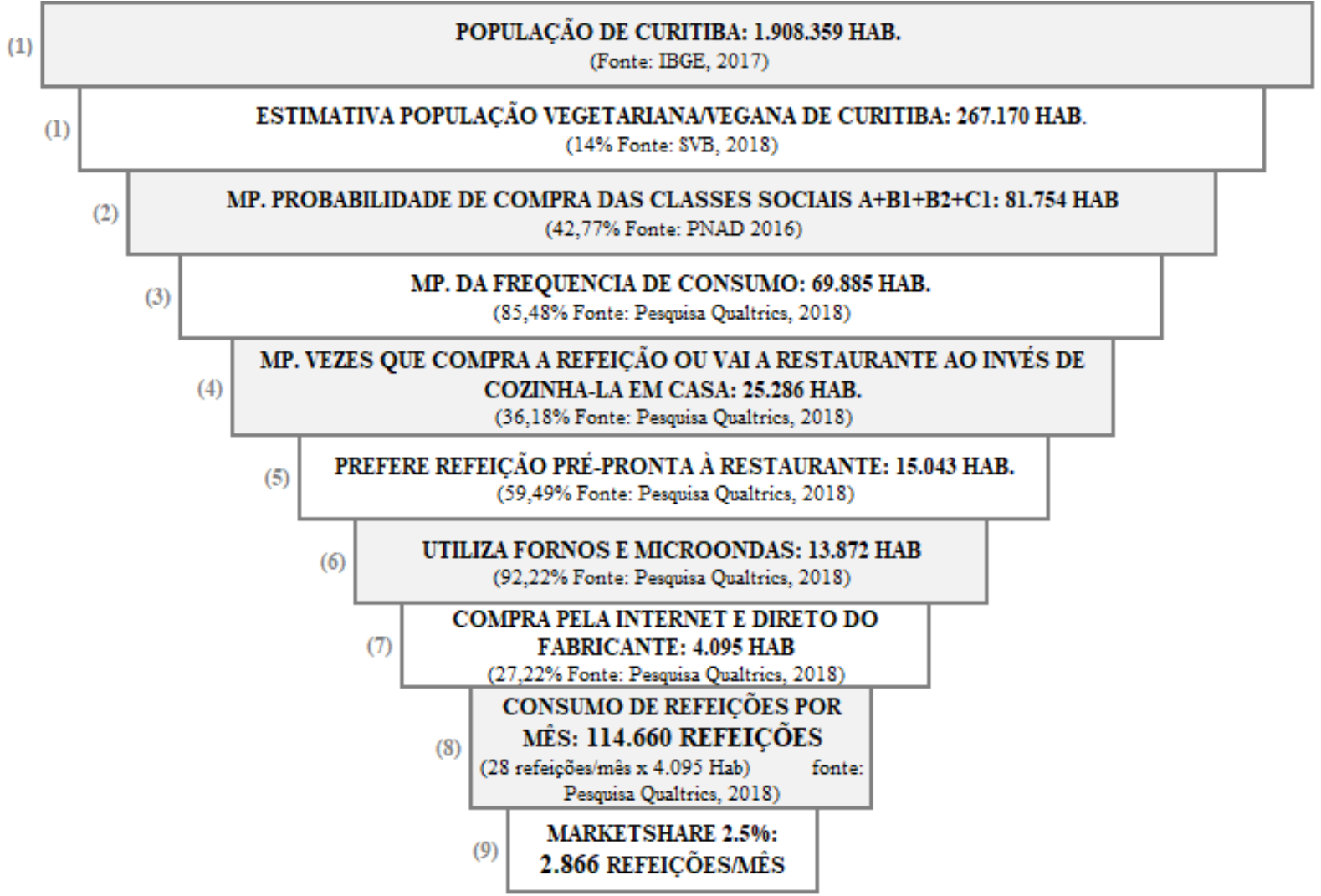

Legenda: MP - Média Ponderada

Este Market share de 2,5\% do público potencial não será alcançado logo no primeiro ano. Ao invés, o crescimento costuma apresentar uma curva ascendente. Experiências anteriores do autor no ramo alimentício indicam que a conquista total da participação de mercado costuma circundar entre 4 e 5 anos. Para as configurações da Beta, estimou-se o alcance completo dos clientes pretendidos a partir do quinto ano de vendas das refeições veganas congeladas, com um potencial crescimento maior nos primeiros anos e adquirindo estabilidade até o ano 5 . A figura 2 indica o crescimento.

Figura 2 - curva de crescimento da demanda ao longo dos anos

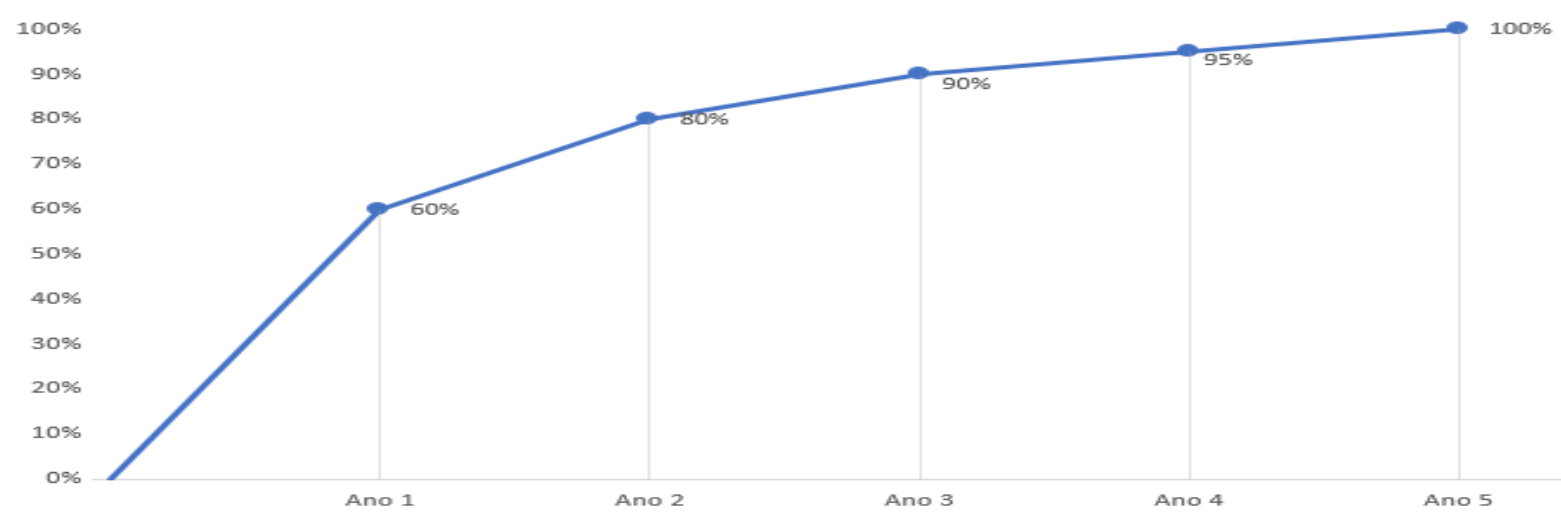




\subsection{ESTRATÉGIA PARA A FIDELIZAÇÃO E AÇÕES DE MARKETING}

A atração e fidelização de clientes para novos produtos é uma importante etapa para conquistar o público. Para tal objetivo, recomenda-se contínuas campanhas através de site, redes sociais e estratégias de fidelização. Através do website que a empresa já possui, pooderão ser disponibilizadas informações que garantam transparência e transmitam confiança aos clientes, incluindo espaços para expor a procedência dos alimentos, promoções, informações sobre missão visão e valores, e uma área com destaque ao processo de fabricação das refeições.

As redes sociais também precisam ter forte presença na comunicação com os clientes. Através do Facebook e Instagram da empresa será desenvolvido o marketing de conteúdo, estratégia que cria engajamento no público alvo através da publicação de conteúdos relevantes objetivando atrair, envolver e gerar uma percepção positiva sobre a marca. O conteúdo publicado não será invasivo, ou seja, explicitando o desejo de vender um produto, mas com intenção de levar benefícios ao leitor, como esclarecimento de dúvidas, exposição de benefícios implícitos, criar discussões, gerar interações, entre outros. Nestes canais também poderão ser realizadas eventuais promoções com sorteio de refeições. A ferramenta WhatsApp também será utilizada pela empresa para facilitar os pedidos de encomendas e estreitar a comunicação.

Outra tática para fidelização dos clientes pode ser a criação de pacotes/combos com 5, 10 e 20 refeições, estratégia que reduz o preço ao consumidor e promove fidelidade. Cada pacote ainda pode incluir brindes, como uma sacola ecológica personalizada da Beta. Outra estratégia pode ser a oferta de refeições em embalagens reutilizáveis de vidro. O objetivo desta embalagem é sanar uma dor dos clientes que não utilizam embalagens plásticas em fornos microondas por acreditarem que estas contaminam a comida durante o aquecimento. As embalagens de vidro ainda visam a sua reutilização pelo consumidores, estimulando a sustentabilidade e preservação ao meio ambiente. Visando a comodidade e praticidade, também poderão ser oferecidas caixas compactas de isolamento térmico do alimento para facilitar o transporte das refeições congeladas entre curtas distâncias.

Dentre as ações de marketing analisadas para o contexto e capacidade da Beta, é possível investir em publicidade, principalmente na internet e se associando a entidades e empresas que ajudarão a tornar a marca mais conhecida, além da participação da empresa em eventos gastronômicos e ações promocionais. Em simultâneo ao site próprio, a Beta poderá investir em redes sociais para expandir a visibilidade da marca. Google, Facebook, Instagram e WhatsApp serão os principais veículos de investimento. No Google Adwords - plataforma da Google que indica sites de acordo com termos pesquisados - sugere-se o investimento de $R \$ 304,00$ por mês para o site da Beta aparecer com prioridade nas buscas por termos relacionados a comida vegana originadas de Curitiba. Segundo estimativas do Google, este investimento tem o potencial de atingir entre 5.825 e 9.729 visualizações por mês e entre 482 a 805 cliques mensais.

No Facebook e Instagram os investimentos serão maiores pelo fato de as pessoas tenderem a passar mais tempo nessas redes sociais. $O$ investimento mensal sugerido é de $R \$ 2.500,00$, quantia que de acordo com as ferramentas, tem o potencial de atingir entre 85 e 540 envolvimentos por publicação no período. O 
perfil de cliente a ser atingido pela publicidade foi definido por homens e mulheres entre 18 e 65 anos, localizados em Curitiba que apresentem interesse nos termos "vegano", "vegetariano" e "alimentação saudável".

Visando adquirir credibilidade à marca, a Beta poderá celebrar parcerias com a SVB e um clube de benefícios de um grande jornal de Curitiba. Trata-se de uma associação sem custos para ambas as partes, em que a Beta concederá descontos de $10 \%$ aos sócios do clube e da SVB na compra unitária de refeições. Em contrapartida, as empresas cedem espaço em seus sites e redes sociais para publicidade da Beta, além de conceder selo de empresas parceiras. Conforme dados das empresas, a taxa de retorno dos associados fica estimada entre $6 \%$ e $10 \%$.

Outra estratégia indicada durante o primeiro ano de comercialização dos novos produtos, é o sorteio de refeições congeladas por mês a potenciais clientes que desenvolverem interações nas redes sociais da empresa e responderem um breve questionário avaliando o produto e informando sugestões. Esta ação tem por objetivo fazer os prospects conhecerem as refeições e ainda obter o feedback das impressões dos clientes. Finalmente, também poderão serão ofertados brindes de sacolas de pano cru reutilizáveis personalizadas com a logomarca da empresa em qualquer combo adquirido. $O$ valor estimado para os brindes, sorteios e as parcerias será de $R \$ 555,00$ mensais. A tabela 6 resume os valores de investimentos em ações de marketing mensais. Todos os valores citados são baseados em cotações realizadas junto às empresas fornecedoras do serviço.

Tabela 6 - estimativa de custos mensais com ações de marketing Custo mensal (R\$)

\section{CONSIDERAÇÕES FINAIS}

O objetivo da presente pesquisa foi identificar as preferências do consumidor vegetariano e vegano no município de Curitiba, averiguar o potencial mercado e demanda vegana/vegetariana no município e apontar estratégias de fidelização e ações de marketing necessárias para atingir este público.

A partir do questionário aplicado aos potenciais consumidores foi possível verificar a percepção quanto as preferências e costumes dos clientes, destacandose a aversão de $7,78 \%$ do público potencial quanto a não aceitação de alimentos na forma congelada, possibilitando a Beta adotar ações preventivas.

A quantificação do mercado potencial facilita o cálculo de estimativas de retorno financeiro com o investimento ao longo de 5 anos, permitindo aferir a viabilidade do projeto com mais acuracidade. Por fim, as indicações de ações de marketing permitem ampliar a visibilidade da empresa e do produto, aumentando o potencial de interesse dos clientes e consequentemente da efetivação da compra. As ações sugeridas podem proporcionar engajamento e envolvimento dos clientes, possibilitando estabelecer fidelização e desenvolvimento de laços com a marca.

Todavia, além das técnicas empregas neste estudo, sugere-se que tomadores de decisões considerem outras informações referentes ao negócio para 
obter-se uma visão ampla sobre o real risco ou sucesso da implementação pretendida.

As análises indicadas na pesquisa reúnem informações importantes para auxiliar a tomada de decisão de gestores quanto a implementação ou não dos novos produtos no mercado, conforme sugerem Papulova \& Gazova (2016). Tais informações podem reduzir possíveis prejuízos por decisões tomadas sem embasamento concreto.

As ações sugeridas nesta pesquisa podem ser adotadas por outras empresas que pretendam ofertar novos produtos ao mercado, pois vislumbram aspectos como apuração do mercado potencial, averiguação das preferências e percepções do consumidor sobre o projeto e possíveis formas de potencializar a efetivação da compra.

Limitaram este estudo a falta de acesso a alguns indicadores e projeções financeiras da Beta, que limitaram as sugestões de ações de marketing. Novas pesquisas nessa temática podem ser desenvolvidas com técnicas diferentes e comparadas com as adotadas nesta investigação para proporcionar ainda mais informações aos gestores no processo de tomada de decisão.

\section{REFERÊNCIAS}

Administradores.com. Falta de tempo afeta $62 \%$ dos brasileiros. Disponível em $<$ http://www.administradores.com.br/noticias/cotidiano/falta-de-tempo-afeta-62-dosbrasileiros/101860/>. Acesso em 26 out. de 2019.

ANDRIOTTI, F. K.; FREITAS, H. M. R.; MARTENS, C. D. P. Proposição de um Protocolo para Estudo sobre a Intuição e o Processo de Tomada de Decisão. Revista de Gestão, 2014.

BARBETTA, P. A. Estatística aplicada às ciências sociais. 2 ed. Editora UFSC: São Paulo, 2002.

BRAZILIAN ASSOCIATION OF RESEARCH COMPANIES - ABEP. Economic classification criterion Brazil. ABEP, v. 1, p. 1-5, 2018.

ANJOS, C.; DE SANTANA, L.; SOUZA, T.; DE OLIVEIRA, L. C. (2014). Avaliação dos fatores que influenciam o consumidor na escolha de restaurantes do tipo. Revista Contextos da Alimentação v. 3, n.1, 2014

CALABRETTA, G.; GEMSER, G.; WIJNBERG, N. The interplay between intuition and rationality in strategic decision making: $A$ paradox perspective. Organization Studies, v. 38, n. 3-4, p. 365-401, 2017.

CARREIRO, J. Mercado vegano cresce $\mathbf{4 0} \%$ ao ano no Brasil. Disponível em: $<$ https://emais.estadao.com.br/blogs/comida-de-verdade/mercado-vegano-cresce40-ao-ano-no-brasil/>. Acesso em: 13 fev. 2020.

DUNCAN, R. B. Characteristics of Organizational Environments and Perceived Environmental Uncertainty. Administrative Science Quarterly, 1972.

FORBES. Millennials Are Driving The Worldwide Shift Away From Meat. Disponível em: <https://www.forbes.com/sites/michaelpellmanrowland/2018/03/23/millennials-moveaway-from-meat/?sh=38b43087a4a4>. Acesso em 15 jan. de 2021. 
IBGE. Pesquisa nacional por amostra de domicílios - síntese de indicadores. v. 57, 2014.

GLOBO CIÊNCIA. Falta de tempo é o principal causador de estresse entre os brasileiros.

$<$ http://redeglobo.globo.com/globociencia/noticia/2012/07/falta-de-tempo-e-oprincipal-causador-de-estresse-entre-os-brasileiros.html>. Acesso em 12 fev. 2021.

GONÇALVES, E.; MACHADO, M.; MARQUES, R. Marketing de relacionamento para fidelizar clientes. Gestão Contemporânea, v. 2, n. (1), 2020.

International Stress Management Association Brasil. Trabalho, Stress e Saúde: o engajamento na prevenção do burnout - da teoria à ação. Disponível em: <http://www.ismabrasil.com.br/congressos/congresso-2015> Acesso em 22 out. de 2019.

LENNERTS, S.; SCHULZE, A.; TOMCZAK, T. The asymmetric effects of exploitation and exploration on radical and incremental innovation performance: An uneven affair. European Management Journal, 2019.

MALEK, L.; UMBERGER, W. Distinguishing meat reducers from unrestricted omnivores, vegetarians and vegans: A comprehensive comparison of Australian consumers. Food Quality and Preference, n. 88, 104081, 2021.

MARQUES, H.; LEVI, R. Funil de vendas: um jeito fácil para você realizar bons negócios. Editora Senac. São Paulo, 2020

MEIRELLES, G. Plano de Marketing: captação e fidelização de clientes do Restaurante" We Poke" IPAM - Instituto Português de Administração de Marketing (Doctoral dissertation), 2020.

MOREIRA, I; ACEVEDO, R. Resistance to consumption and veganism: A study about motivations, values, and feelings. Revista Gestão \& Tecnologia, v. 15, n. 2, p. 50-67, 2015.

OECD/EUROSTAT. Oslo Manual. OCDE. 2018.

OLIVEIRA, P.; GOIS, I.; GOLDSTEIN, M. Aplicação do funil de vendas para melhoria de engajamento em um SVA. Revista da Universidade Vale do Rio Verde, v. 16, n. 2, 2018.

PAPULOVA, Z.; GAZOVA, A. Role of Strategic Analysis in Strategic DecisionMaking. Procedia Economics and Finance, 2016.

SALDAÑA, J. The Coding Manual for Qualitative Researchers. 2 Ed. Sage, 2013.

SAMBA, C.; TABESH, P.; THANOS, I; PAPADAKIS, V. Method in the madness? A meta-analysis on the strategic implications of decision comprehensiveness. Strategic Organization, 2020.

SVB - Sociedade Vegana Brasileira. Vegetarianismo. Disponível em: <https://www.svb.org.br/vegetarianismo1/o-que-e>. Acesso em 22 out. de 2019.

TERRA, N. M.; BARBOSA, J. G. P.; BOUZADA, M. A. C. A influência da inovação em produtos e processos no desempenho de empresas brasileiras. Review of Administration and Innovation - RAI, 2015. 
TIDD, J.; BESSANT, J. Gestão da inovação. 5a ed. ed. Porto Alegre: Bookmen, 2015.

TREFFERS, T.; KLARNER, P.; HUY, Q. N. Emotions, time, and strategy: The effects of happiness and sadness on strategic decision-making under time constraints. Long Range Planning, 2020.

VIANNA, N. W. H.; ALMEIDA, S. R. De. A decisão de internacionalizar. Revista Eletrônica de Negócios Internacionais da ESPM, 2011.

WANG, W.; LU, W.; KWEH, Q.; LEE, J. Management characteristics and corporate performance of Chinese chemical companies: the moderating effect of managerial ability. International Transactions in Operational Research, v. 28, n. 2, p. 976995. 2021.

WORLDATLAS. Countries With The Highest Rates Of Vegetarianism. Disponível em: $\quad<$ https://www.worldatlas.com/articles/countries-with-the-highest-rates-ofvegetarianism.html>. Acesso em 16 out. de 2020. 